\title{
Stroop effect in words that differ from color words in one letter only
}

\author{
URI BIBI, JOSEPH TZELGOV, and AVISHAI HENIK \\ Ben-Gurion University of the Negev, Beer-Sheva, Israel
}

\begin{abstract}
In two experiments, participants named the color of a colored word, which was a Hebrew color word or a word in Hebrew that was different from a color word in one letter only. The magnitude of the Stroop effect increased with the location of the changed letter. It was smallest when the first letter of the color word was replaced, resulting in a noncolor word, and it was largest when the last letter was replaced. These results challenge the assumption that automatic reading, as indicated by the Stroop effect, can be explained exclusively by memory retrieval accounts of automaticity. The results also have implications for the sources of facilitation and inhibition in the Stroop effect.
\end{abstract}

There is an agreement among researchers that in the early stages of skill acquisition, performance is based on algorithmic processing - that is, mental computation. Yet, when it comes to performance that is based on advanced training, and specifically to automaticity, researchers disagree on the involved mechanism. There are two main approaches concerning the mechanism of automatic processing. One, exemplified by MacKay (1982; see also Anderson, 1982, 1992), is process-based and claims that training results in improving the processing algorithm applied by novices or in the evolvement of new, more efficient processing routines. Therefore, automatic processing means applying mental computations faster and more efficiently.

Another approach, proposed by Schneider (1985), Schneider and Detweiler (1987), and Logan (1988) in his instance theory, is memory based. This approach claims that automatization result in a single-step retrieval from memory. The results of Kramer, Strayer, and Buckley (1990) and, in particular, those of Tzelgov, Henik, Sneg, and Baruch (1996) imply that automatic reading cannot be explained exclusively by memory retrieval. In concurrence with their work, this report provides additional evidence that automatic processing can reflect mental computation, rather than mental retrieval.

Reading is a cognitive skill frequently assumed to be automatic, at least when performed by skilled adults. The dual-route approach to reading (e.g., Davelaar, Coltheart, Besner, \& Jonasson, 1978; Forster \& Chambers, 1973) assumes that skilled readers employ two routes: the direct

\footnotetext{
The authors thank Derek Besner, Art Kramer, Thomas Palmeri, and Max Coltheart for very helpful comments on an earlier version of this article and also Orly Rubinstein for providing the information needed for neighbors analysis. The article also benefited from an excellent $e$ mail discussion with Max Coltheart. Correspondence concerning this article should be addressed to U. Bibi, Department of Behavioral Sciences. Ben-Gurion University of the Negev, Beer-Sheva, 84105, Israel (e-mail: bibi@bgumail.bgu.ac.il).
}

or lexical route, which enables mapping from the visual pattern corresponding to a word directly into the lexicon (and thereby, to speech and semantics), and the nonlexical route, in which the access to the lexicon speech is mediated by grapheme-to-phoneme conversion. One possibility is that automatic reading is based exclusively on the direct route. This corresponds to the single-step retrievalfrom-memory explanations of automaticity, in the sense of single-step mapping from a familiar visual pattern to the lexicon. Alternatively, it may be that automatic reading also reflects the algorithmic (i.e., nonlexical) route that is based on grapheme-to-phoneme conversion. This is implied by Coltheart and his colleagues' (e.g., Coltheart, Curtis, Atkins, \& Haller, 1993; Coltheart \& Rastle, 1994) implementation of the dual-route framework in their dualroute cascade (DRC) model. In DRC, the outputs of both the lexical (memory retrieval) and the nonlexical (algorithmic) routes contribute to skilled reading.

The Stroop effect is usually taken as an indication of automatic reading (see MacLeod, 1991, for a review). In the Stroop task (Stroop, 1935), the participant is asked to report the color of the ink of a written stimulus while ignoring its meaning. The Stroop effect is reflected by longer reaction times (RTs) for the incongruent trials (e.g., the word RED written in blue) than for the congruent trials (e.g., RED written in red ink). Recently, several authors (e.g., Algom, Dekel, \& Pansky, 1996; Besner, Stolz, \& Boutilier, 1997) challenged the idea that the Stroop effect indicates processing that cannot be avoided. We wish to point out that even if their critique is correct, we believe that the Stroop effect reveals automatic reading by showing that the participant reads despite the instructions. In other words, the Stroop effect shows that reading has the central feature common to all automatic processes (Bargh, 1992): It can run without intentional monitoring (see Tzelgov, 1997, for a further discussion of this issue).

Consider what would happen if words orthographically similar to color names were to be used in a Stroop 
task. What if, instead of the (color) word RED, we used the words BED or RET ${ }^{1}$ Note that these two words differ from the color word RED by one letter only-the first letter in BED and the last letter in RET. According to the memory-based approach to automaticity, no Stroop effect should occur for either of them.

Palmeri (1997) proposed an extension of Logan's (1988) instance theory, according to which a presented stimulus activates not only instances of the specific stimulus stored in memory, but also other stimuli similar to the target presented. If similarity between words is computed as an increasing function of the overlap in the letters between two words and as a decreasing function of their difference (see Tversky's, 1977, contrast model), one should expect that the Stroop effect would not differ as a function of the replaced letter location. If one assumes that the mental algorithm (that computes the meaning of the word by processing the letters sequentially from left to right) is automatically applied, one should expect a larger Stroop effect for RET than for BED. Such an effect could also be explained by Palmeri's exemplar-based random walk model, by assuming that the similarity is computed after the letters have been weighted (in a decreasing order) according to their left-to-right location. In our view, however, this would still mean that automatic reading is based on a (minimal two-step) computational process. In the first step, the word is decomposed into the component letters, which are assigned differential weights. In the second step, similarity to exemplars stored in memory is computed.

There are several indications that a single letter can bias processing in the Stroop task. Regan (1978) has shown that even a single letter of a color word could facilitate (or inhibit) color naming. In her study (Experiment 2), participants named the color of compatible, incompatible, or control letters. Both facilitation and inhibition were obtained. Unfortunately, this Experiment employed only the first letter of the color word, and therefore, no conclusion could be made concerning the importance of the letter's location in the word.

Singer, Lappin, and Moore (1975) employed stimuli in which the first, middle, or last two letters of the color word were presented. Although interference produced by the first two letters was the largest, there was no significant difference between the interference produced by the two middle or the two last letters. These results must be evaluated carefully, because the experiment employed a continuous Stroop paradigm in which RTs were recorded for a whole page of stimuli.

\section{EXPERIMENT 1}

Algorithmic models usually assume that there are sequential components in the processing of information while performing a given task. Coltheart et al.'s (1993) DRC model of reading has an algorithmic component operationalized as the nonlexical route that operates serially, letter by letter. Recently, Coltheart, Woollams, Kinoshita, and Perry (1999) ran an experiment in which participants were presented with words that were semantically unrelated to colors but shared with color words the first, the last, or no phoneme (e.g., for RED: RAT, POD, KIT). The words appeared in the color that had the shared phoneme - that is, in the case of the example provided, the words appeared in red. According to the DRC model, the response red should be faster for RAT than for POD, because even if the activation of the phoneme $\mathrm{R}$ from the lexical route was equal to that of $D$, the activation from the nonlexical route would be available earlier for $R$ than for $D$. Moreover, the color naming of POD should be faster than that of KIT, because in the case of POD, the nonlexical route would activate the third letter of RED. The predictions were supported by the data and therefore are consistent with the claim that automatic processing can reflect algorithmic letter-by-letter computations.

In the present experiment, we tested another prediction following from the assumption of automatic reading based on algorithmic processing. If automatic reading can be based on the nonlexical route, as was suggested by Coltheart et al.'s (1999) findings, then since English is read from left to right, one can predict that when we see the first letter $B$ in the word BED, all words beginning with $B$ are activated, whereas all other words are inhibited. Therefore, the possibility of selecting RED at the end of the processing is limited. Following the same logic, when the word RET is presented, while processing the letters RE, all words beginning with RE would be facilitated, as well as the word RED, but then when processing the letter T, we would claim that the word RED is inhibited. Since the word RED was facilitated in most of the processing stages, we would claim that the possibility of choosing RED in the present case is higher than the possibility of choosing RED in the previous example. Given such a model of processbased automaticity, one would expect a larger Stroop effect for words in which a later consonant was changed, owing to the stronger activation of the irrelevant color word. Keeping in mind this process-based scheme for automatic processing, we ran two experiments in which participants performed a Stroop task that included stimuli that were words orthographically related to color names.

Berent and Perfetti (1995) presented a two-cycle model of phonology assembly, in which they claim that word processing involves two different mechanisms, one for vowels and one for consonants. They argue that vowel processing is controlled, whereas consonant processing is automatic. Although the aim of their theory was to describe the process of reading English, on the basis of their theory, we used Hebrew words (color words and words orthographically similar to color words) composed of four letters, of which a vowel was in the third location. In all the color words included in our experiment, the same vowel (o) appeared in the same (third) location. Thus, we held the vowels phase constant while manipulating the consonants phase. To be more specific, in our experiment, we used four-letter color words and noncolor words different from color words in one letter-in the first, the second, or the fourth location. 
Table 1

The Stimuli in Hebrew and their Translations Into English

\begin{tabular}{|c|c|c|c|c|}
\hline Color Word & Red & Blue & Green & Yellow \\
\hline In Hebrew & 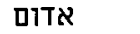 & 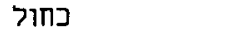 & ירוק & צהוב \\
\hline Change in the first letter & 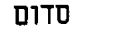 & מחול - - - - - - 1 & שרוק & אהוב \\
\hline Translation & Sodom* & dance & whistle & love \\
\hline Change in the second letter & אטום - - אטום & כבול & 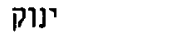 & צלוב \\
\hline Translation & nuclear & tied & sucked & crossed \\
\hline Change in the fourth letter & 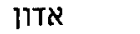 & 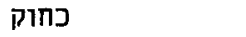 & ירום & 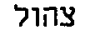 \\
\hline Translation & gentleman & according to the law & will get higher & be happy \\
\hline
\end{tabular}

* סדום is the Hebrew name for the biblical city of Sodom.

\section{Method}

Participants. Twelve undergraduate students at Ben-Gurion University of the Negev participated in the experiment for course credit. All the participants were Hebrew native speakers, and all had normal or corrected-to-normal color vision.

Stimuli. The different types of word stimuli appear in Table 1. As can be seen in the first row of Table 1, we used the color words (in Hebrew) RED, BLUE, GREEN, and YELLOW. The Hebrew names of the colors appear in the second row. In the third row appear Hebrew words differing in their first letter from the corresponding color words. The English translations of these words appear in the fourth row. In the fifth row appear Hebrew words differing in their second letter from the corresponding color words, with their English translations appearing in the sixth row. In the seventh row appear Hebrew words differing in their fourth letter from the relevant color words, and their translations appear in the eighth row.

To summarize, we used four color words and noncolor words different from each of the color words in the first, the second, and the fourth letter. In addition, a string of four identical Hebrew letters (Shin) was used as a neutral stimulus for all groups. Each stimulus, including the neutral, appeared in each of the four colors.

Procedure and Apparatus. The experiment consisted of 288 trials. For each type of word (color word and the three sets of noncolor words with a different location of the replacing letter), there were 72 trials, 24 in each of the three congruency conditions (congruent, neutral, and incongruent) of the experiment.

The participants sat in front of an Olivetti screen, which was connected to an IBM compatible Olivetti M290-30 computer. The participants were told to ignore the meaning of the word and to name the color of the stimulus. Responses were collected via an L.P.S. 700 clock card within the computer.

The experiment started with 24 practice trials, in which errors were corrected. Each trial (practice or experimental) consisted of a fixation point that appeared for $300 \mathrm{msec}$ and was immediately followed by $300 \mathrm{msec}$ of a black screen. The stimulus appeared at the center of the screen and stayed on until the onset of the response. The experimenter coded the participant's response. The next trial began after an additional $300 \mathrm{msec}$.

\section{Results}

A two-way analysis of variance (ANOVA) was conducted, with type of word and congruency as withinsubjects factors. Since there was no indication of a speedaccuracy tradeoff and the percentage of errors was low, averaging $2.3 \%$, we focused our analysis on RTs. Table 2 presents the mean RTs and mean percentage of errors in the various experimental conditions.

As can be seen in Table 2, the Stroop effect increased with the location of the changed consonant. This visual impression was supported by the interaction between stimulus type and congruency $\left[F(6,66)=14.34, M S_{\mathrm{e}}=615.58\right.$, $p<.001]$. Thus, although the main effects of congruency and type of stimulus were significant $[F(2,22)=70.44$, $M S_{\mathrm{e}}=799.8, p<.001$, and $F(3,33)=3.38, M S_{\mathrm{e}}=875.77$, $p<.02$, respectively], we focused our analysis on the interaction. Further analysis showed that the RT difference between the congruent and the incongruent conditions increased linearly with the location of the changed consonant $\left[F(1,11)=42.18, M S_{\mathrm{e}}=1,140.82, p<.001\right]$. This linear increase of the Stroop effect with the location of the changed consonant explained $90.8 \%$ of the sum of squares of the interaction. ${ }^{2}$

Table 2

Mean Reaction Times (RTs, in Milliseconds) and Percentage of Errors for the Various Conditions of Experiment 1

\begin{tabular}{lcccc} 
Condition Type & $\begin{array}{c}\text { Location of the Replaced Letter } \\
\text { (From Right to Left) }\end{array}$ & RT & \%Error & Stroop Effect \\
\hline Neutral & & 672 & 0.6 & \\
Congruent & 1 & 672 & 1.7 & 2 \\
Incongruent & & 674 & 1.4 & \\
Congruent & 2 & 663 & 2.5 & 50 \\
Incongruent & & 713 & 3.2 & \\
Congruent & 4 & 660 & 2.8 & 81 \\
Incongruent & & 741 & 2.4 & \\
Congruent & & 640 & 2.4 & 125 \\
Incongruent & & 765 & 4.4 & \\
\hline
\end{tabular}

*Congruent and incongruent stimuli using color words. 
Table 3

\begin{tabular}{|c|c|c|c|c|}
\hline Condition Type & $\begin{array}{l}\text { Location of the Replaced Letter } \\
\text { (From Right to Left) }\end{array}$ & RT & $\%$ Error & Stroop Effect \\
\hline Neutral & & 613 & 1.7 & \\
\hline $\begin{array}{l}\text { Congruent } \\
\text { Incongruent }\end{array}$ & 1 & $\begin{array}{l}624 \\
668\end{array}$ & $\begin{array}{l}0.8 \\
1.0\end{array}$ & 44 \\
\hline $\begin{array}{l}\text { Congruent } \\
\text { Incongruent }\end{array}$ & 2 & $\begin{array}{l}598 \\
675\end{array}$ & $\begin{array}{l}0.8 \\
2.8\end{array}$ & 77 \\
\hline $\begin{array}{l}\text { Congruent } \\
\text { Incongruent }\end{array}$ & 4 & $\begin{array}{l}590 \\
685\end{array}$ & $\begin{array}{l}1.0 \\
2.9\end{array}$ & 95 \\
\hline Incongruent & $0^{*}$ & 715 & 4.2 & \\
\hline
\end{tabular}

*Incongruent stimuli using color words.

\section{EXPERIMENT 2}

One could argue that the participants in Experiment 1 tended to read the words presented because of the presence of congruent color stimuli (i.e., RED written in red). Under the assumption that word reading is faster than color naming, reading the word would speed up the response for such stimuli and, therefore, might result in a tendency to read the words presented. In order to show that the results obtained do not depend on this strategy, we ran Experiment 2, which was similar to Experiment 1 in all features but did not include congruent color words.

\section{Method \\ Twenty-four undergraduate students at Ben-Gurion University of the Negev participated in the experiment. The experiment was sim- ilar to Experiment 1 in all features, except for the exclusion of con- gruent stimuli. Thus, the experiment consisted of 264 trials. For each type of noncolor word, there were 48 trials, 24 in each of the two congruency conditions (congruent and incongruent). Color words were presented only in the incongruent condition ( 24 trials). Ninety-six nonword neutral trials were also included.}

\section{Results}

Table 3 presents the mean RTs and mean error percentages in the various experimental conditions.

Since there was no indication of a speed-accuracy tradeoff and the percentage of errors was low, averaging $1.9 \%$, only RTs were analyzed. A two-way ANOVA, with type of word and congruency as within-subjects factors, was performed on RTs and verified the picture emerging from Table 3: A significant Stroop effect $[F(1,23)=$ $\left.10.90, M S_{\mathrm{e}}=14,320.11, p<.003\right]$ moderated by the location of the changed consonant $\left[F(2,46)=9.43, M S_{\mathrm{e}}=\right.$ $820.80, p<.001]$ was found. Further analysis indicated that the difference in RTs between the congruent and the incongruent conditions increased linearly with the location of the changed consonant $\left[F(1,23)=24.68, M S_{\mathrm{e}}=\right.$ $15,050.04, p<.001]$. This linear increase of the Stroop effect with the location of the changed consonant explained $91.8 \%$ of the sum of squares of the interaction.

\section{GENERAL DISCUSSION}

In both experiments, we found that the magnitude of the Stroop effect increased linearly with the locations of the changed consonant - the later the location of the changed consonant, the larger the Stroop effect. These results suggest that some kind of a serial mechanism is involved in automatic reading as indicated by the Stroop effect.

Andrews (1997) reported that when a word has many orthographic neighbors, its RT for lexical decision and naming tasks is facilitated. Hence, this effect could explain our findings, if the number of neighbors of color words were to be negatively correlated with the position of the word in which a color word and its neighbor differ, because the neighbors might cause activation of the color words. Overall, we found that the color words used in our experiments have 20 orthographic neighbors differing in the first letter position, 15 neighbors differing in the second letter position, and only 12 neighbors differing in the third letter position when replacing the last letter. It follows that the correlation between the magnitude of the Stroop effect and the location distinguishing between a color word and its neighbor is positive rather than negative, contrary to what would be predicted on the basis of the neighbors effect (Andrews, 1997).

From the viewpoint of models of reading, our results support the notion that automatic reading may be based on the nonlexical route. Coltheart et al. (1999) have recently run an experiment in which they asked the participants what the color of the ink was for stimuli that were color-unrelated words but shared the first, the last, or no letter with the color name they had to pronounce. It was found that the color was identified faster when it shared a phoneme with the printed word. This effect was stronger when the first phoneme was the shared one. These findings correspond to those of the congruent condition in our experiments, which show that reading via the nonlexical route can facilitate color naming and that facilitation increases when the consonant in which a given word differs from the color to be named appears later in this word. 
Coltheart et al. (1999) also simulated these effects in their DRC model by setting to zero the connections from the letter level to the orthographic lexicon. This shuts off the lexical route, leaving the nonlexical route unaffected, or in other words, it allows for automatic reading via the nonlexical route only.

Our experiments also show that automatic reading via the nonlexical route can also inhibit color naming and that this inhibition is sensitive to the location of the replaced letter. The simple main effect of the location of the changed consonant was significant in the incongruent condition of both experiments $\left[F(3,33)=12.00, M S_{\mathrm{e}}=\right.$ $18,537.36, p<.001$, and $F(3,69)=8.09, M S_{\mathrm{e}}=$ $10,206.08, p<.001$, for Experiments 1 and 2, respectively]. This might also be due to the print-to-speech (phonological) conversion process: The later the location of the changed consonant (as in the case of RET and BED for the color word RED), the more similar the resulting sequence of phonemes to the corresponding color word (RED). Therefore, such a word will be more strongly activated in the case of RET than in the case of BED and will inhibit RED more, owing to the semantic relation between the two color words. According to this interpretation, the inhibitory component of the effect found reflects semantic activity, which was caused by input from the nonlexical route. Coltheart et al. (1999) pointed out that there are two different components of the Stroop effect-a phonological component that causes a larger effect in pronounceable letter strings than in nonpronounceable ones (Bakan \& Alperson, 1967) and a semantic component that results in a larger effect when the presented word is more similar to a color word (Klein, 1964). It follows from our analysis that the nonlexical route contributes to the phonological component via facilitation and to the semantic component via inhibition.

The serial characteristic of the nonlexical route is consistent with our view that it may be seen as applying algorithmic processing. Memory retrieval views of automaticity do not predict the different magnitude of the Stroop effect as a function of (the changed) letter location. Therefore, we can rule out the possibility that the automatic processing of the words was caused by retrieval from memory. Palmeri's (1997) extension of the instance theory could explain the present results by assuming that the computation of similarity between words is based on differential weighting of the letters according to their location in the word. Such computation of similarity would imply algorithmic (i.e., multistep) processing of information stored in memory, rather than single-step retrieval. Thus, we believe that the results are hard to reconcile with single-step retrieval accounts of automaticity. Therefore, we propose that these results support the notion that the Stroop effect can indicate automatic processing based on mental computation.

To sum up, our results point in the direction of processbased automaticity. That does not mean that automatic processing is always or exclusively based on multistep algorithmic processing. We believe, however, that our results do show that automatic processing is not constrained to single-step memory retrieval.

\section{REFERENCES}

Algom, D., Dekel, A., \& Pansky, A. (1996). The perception of number from the separability of the stimulus: The Stroop effect revisited. Memory \& Cognition, 24, 557-572.

Anderson, J. R. (1982). Acquisition of cognitive skill. Psychological Review, 89, 369-406.

Anderson, J. R. (1992). Automaticity and the ACT theory. American Journal of Psychology, 105, 165-180.

ANDrEws, S. (1997). The effect of orthographic similarity on lexical retrieval: Resolving neighborhood conflicts. Psychonomic Bulletin \& Review, 4, 439-461

BaKan, P., \& Alperson, B. (1967). Pronounceability, attensity, and interference in color-word test. American Journal of Psychology, 80, 416-420.

BARGH, J. (1992). The ecology of automaticity: Towards establishing the conditions needed to produce automatic processing effect. American Journal of Psychology, 105, 181-199.

Berent, I., \& Perfetti, C. A. (1995). A rose is a REEZ: The twocycles model of phonology assembly in reading English. Psychological Review, 102, 146-184.

Besner, D., Stolz, J. A., \& Boutilier, C. (1997). The Stroop effect and the myth of automaticity. Psychonomic Bulletin \& Review, 4 221-225.

Coltheart, M., Curtis, B., Atkins P., \& Haller, M. (1993). Models of reading aloud: Dual-route and parallel-distributed-processing approaches. Psychological Review, 100, 589-608.

Coltheart, M., \& Rastle, K. (1994). Serial processing in reading aloud: Evidence for dual-route models of reading. Journal of Experimental Psychology: Human Perception \& Performance, 20, $1197-$ 1211

Coltheart, M., Woollams, A., Kinoshita, S., \& Perry, C. (1999). A position-sensitive Stroop effect: Further evidence for a left-to-right component in print-to-speech conversion. Psvchonomic Bulletin \& Review, 6, 456-463.

Davelaar, E., Coltheart, M., Besner, D., \& Jonasson, J. T. (1978). Phonological recoding and lexical access. Memory \& Cognition, 6, 391-402.

Forster, K. I., \& Chambers, S. M. (1973). Lexical access and naming time. Journal of Verbal Learning \& Verbal Behavior, 12, 627-635.

KLEIN, G. S. (1964). Semantic power measured through the interference of words with color-naming. American Journal of Psychology, 77, 576-588.

Kramer, A. F., Strayer, D. L., \& Buckley, J. (1990). Development and transfer of automatic processing. Journal of Experimental Psychology: Human Perception \& Performance, 16, 505-522.

LOGAN, G. D. (1988). Toward an instance theory of automatization. Psychological Review, 95, 492-527.

MaCKAY, D. G. (1982). The problem of flexibility, fluency and speed-accuracy trade-off in skilled behavior. Psychological Review, 89, 483-486.

MACLEOD, C. M. (1991). Half a century of research on the Stroop effect: An integrative review. Psychological Bulletin, 109, 163-203.

PALMERI, T. J. (1997). Exemplar similarity and the development of automaticity. Journal of Experimental Psychology: Learning, Memory, \& Cognition, 23, 324-354.

REGAN, J. (1978). Involuntary automatic processing in color-naming tasks. Perception \& Psychophysics, 24, 130-136.

SCHNEIDER, W. (1985). Toward a model of attention and the development of automatic processing. In M. I. Posner \& O. S. M. Martin (Eds.), Attention and performance XI (pp. 475-492). Hillsdale, NJ: Erlbaum 
SCHNEIDER, W., \& DETWEILER, M. (1987). A connectionist/controlled approach to working memory. In G. H. Bower (Ed.), The psychology of learning and motivation (Vol. 21, pp. 53-119). New York: Academic Press.

Singer, M. H., LapPin, J. S., \& Moore, L. P. (1975). The interference of various word parts on color naming in the Stroop test. Perception \& Psychophysics, 18, 191-193.

Stroop, J. R. (1935). Studies of interference in serial verbal reactions. Journal of Experimental Psychology, 18, 643-662.

TVersky, A. (1977). Features of similarity. Psychological Review, 84, 327-352.

Tzelgov, J. (1997). Specifying the relations between automaticity and consciousness: A theoretical note. Consciousness \& Cognition, 6 , $441-451$.

Tzelgov, J., Henik, A., Sneg, R., \& Baruch, O. (1996). Unintentional word reading via the phonological route: The Stroop effect with cross-script homophones. Journal of Experimental Psychology: Learning, Memory, \& Cognition, 22, 336-349.

\section{NOTES}

1. Let us assume, just for the sake of argument, that RET is a word in English of equal frequency as BED.

2. A similar analysis was run for both facilitation and inhibition, and the results were similar to those of the Stroop effect. We did not report those results, owing to the dependence of the two components.

3. In the DRC model, this is mediated by the phonological lexicon.

(Manuscript received January 20, 1999; revision accepted for publication October $18,1999$. 